\title{
Annelid Distal-less/Dlx duplications reveal varied post-duplication fates
}

\author{
Carmel McDougall ${ }^{1,2,3}$, Natalia Korchagina ${ }^{2}$, Jonathan L Tobin ${ }^{2}$ and David EK Ferrier ${ }^{1 *}$
}

\begin{abstract}
Background: Dlx (Distal-less) genes have various developmental roles and are widespread throughout the animal kingdom, usually occurring as single copy genes in non-chordates and as multiple copies in most chordate genomes. While the genomic arrangement and function of these genes is well known in vertebrates and arthropods, information about Dlx genes in other organisms is scarce. We investigate the presence of Dlx genes in several annelid species and examine Dlx gene expression in the polychaete Pomatoceros lamarckii.

Results: Two Dlx genes are present in P. lamarckii, Capitella teleta and Helobdella robusta. The C. teleta Dlx genes are closely linked in an inverted tail-to-tail orientation, reminiscent of the arrangement of vertebrate Dlx pairs, and gene conversion appears to have had a role in their evolution. The H. robusta Dlx genes, however, are not on the same genomic scaffold and display divergent sequences, while, if the $P$. lamarckii genes are linked in a tail-to-tail orientation they are a minimum of 41 kilobases apart and show no sign of gene conversion. No expression in $P$. lamarckii appendage development has been observed, which conflicts with the supposed conserved role of these genes in animal appendage development. These Dlx duplications do not appear to be annelid-wide, as the polychaete Platynereis dumerilii likely possesses only one Dlx gene.

Conclusions: On the basis of the currently accepted annelid phylogeny, we hypothesise that one Dlx duplication occurred in the annelid lineage after the divergence of $P$. dumerilii from the other lineages and these duplicates then had varied evolutionary fates in different species. We also propose that the ancestral role of Dlx genes is not related to appendage development.
\end{abstract}

\section{Background}

Dlx genes are homeobox genes that were first discovered in Drosophila melanogaster [1] and are best known for their role in appendage development in a wide range of taxa [2-4]. This role is one of several, however, as Dlx genes also have roles in nervous system development and early embryogenesis [2,5-10]. Dlx genes are widespread throughout Metazoa and are found in early branching lineages such as cnidarians [11-13] and placozoans [14]. It appears, therefore, that the Dlx gene evolved early in metazoan evolution, before the divergence of protostomes and deuterostomes, but probably after the divergence of sponges, which most likely lack a Dlx gene [15].

\footnotetext{
* Correspondence: dekf@st-andrews.ac.uk

${ }^{1}$ The Scottish Oceans Institute, University of St Andrews, East Sands, St Andrews KY16 8LB, UK

Full list of author information is available at the end of the article
}

Only one Dlx gene has been discovered in the genome thus far in protostomes, echinoderms, and cephalochordates $[6,10,16]$. Therefore, it is likely that a single copy of the gene is the ancestral state for bilaterians. Mice and humans have three pairs of Dlx genes, which exist in a tail-to-tail arrangement linked to a Hox cluster (the HoxC cluster has no linked Dlx genes; [2]). It is thought that the ancestral chordate Dlx gene was linked to the Hox cluster, underwent a gene-specific duplication and inversion, and the Dlx gene pair was then duplicated during the whole genome duplications that occurred in the vertebrate lineage $[2,17,18]$. In support of this hypothesis, it appears that Dlx2, Dlx3 and Dlx5 form one paralogous group and that Dlx1, Dlx4 and Dlx6 form another $[17,19]$. The urochordate Ciona intestinalis possesses three Dlx genes, two of which are arranged in a tail-to-tail orientation. All three of the genes are closely linked to CiHox 13 and CiHox 12 (the Hox cluster is dispersed in C. intestinalis, and CiHox 13 and
C Biomed Central

(c) 2011 McDougall et al; licensee BioMed Central Ltd. This is an Open Access article distributed under the terms of the Creative Commons Attribution License (http://creativecommons.org/licenses/by/2.0), which permits unrestricted use, distribution, and reproduction in any medium, provided the original work is properly cited. 
CiHox12 exist as a bigene cluster; [20]). The divergent nature of the $C$. intestinalis Dlx sequences has made the deduction of clear gene orthologies difficult, but it is thought that the paired ascidian Dlx genes are a result of the same duplication that led to the paired arrangement of Dlx genes in the vertebrates [20]. The cephalochordate amphioxus possesses only one Dlx gene, which is linked to the Hox cluster [21] and is thought to represent the pre-Dlx duplication state. To date, there are no documented cases of Dlx gene duplications outside the chordates.

The bulk of our knowledge about Dlx gene expression, function, and genomic location is from vertebrates, where Dlx has a large range of roles, including the control of limb formation, differentiation of neuronal subsets and various novel functions relating to the neural crest, such as the development of craniofacial structures (reviewed in [2]). Much less is understood about Dlx genes in invertebrates, but the information that is available comes primarily from $D$. melanogaster, and partly from other arthropods and the nematode Caenorhabditis elegans [5,6,22-24], all of which belong to only one of the two protostome super-phyla, the Ecdysozoa. Our understanding of Dlx in the second protostome superphylum, the Lophotrochozoa, is more rudimentary. A cross-reactive Dlx antibody [25] has been used in both molluscs and annelids, and distinct staining patterns are consistent with these organisms possessing a Dlx gene $[3,9]$. Fragments of Dlx have been cloned from two molluscs [26], and a Dlx gene has been isolated in the annelids P. dumerilii [27] and Neanthes arenaceodentata [28]. Interestingly, the three Dlx expression studies performed in annelids show somewhat different expression patterns; in Chaetopterus variopedatus the Dlx antibody recognises regions in the parapodial rudiments as well as in the neurogenic ectoderm [3], in N. arenaceodentata in-situ hybridisation shows $N v D l l$ expression in the proximal part of appendages and in the brain [28], whereas in $P$. dumerilii in-situ hybridisation indicates that $P d u D l x$ (referred to in the original paper as $P d u D l x 1)$ is expressed in broad regions in the lateral ectoderm which is interpreted to be at the border of neurogenic and non-neurogenic ectoderm [27]. Each of these studies examine restricted developmental stages, making comparisons between the organisms difficult. Thus, the function of Dlx in annelids is poorly understood, as is the extent of its variation between species. In addition, there is no published information about the genomic organisation of Dlx genes in any lophotrochozoan species.

Here we undertake a survey of Dlx genes in the polychaete annelids $P$. lamarckii and $P$. dumerilii, and identify Dlx genes in the genome assemblies of C. teleta and $H$. robusta. All of these species, with the exception of $P$. dumerilii, possess two Dlx genes. In C. teleta, the two Dlx genes exhibit a vertebrate-like tail-tail gene pair arrangement and show evidence of gene conversion, whereas there is no evidence for the close linkage of $P$. lamarckii or $H$. robusta Dlx genes, which correlates with a lack of evidence for gene conversion in these species. We propose that a duplication of an ancestral Dlx gene took place early in annelid evolution, after the divergence of the $P$. dumerilii lineage from the other annelid lineages, and the subsequent divergence of the fates of these duplicated genes. The $P$. lamarckii genes are expressed in presumptive neural cells, but are not detected during appendage development. The duplication of Dlx genes and their apparent absence from appendage development mean that further characterisation of invertebrate Dlx genes is needed, and that evolutionary scenarios based on the assumption of single Dlx genes in protostomes and a near universal role in appendage development need to be re-assessed.

\section{Results}

\section{P. lamarckii Dlx genes}

Shotgun sequencing of Dlx positive phage clones and subsequent RACE on identified homeodomain sequences revealed two distinct genes with homology to Dlx. PlaDlxa [Genbank: accession numbers JN175271 and JN175273] encodes a 380 amino acid protein, whereas PlaDlxb [Genbank: accession numbers JN175272 and JN175274] encodes a 396 amino acid protein. Each gene encodes a 60 amino acid homeodomain and is comprised of three exons, with the second intron between amino acids 44 and 45 of the homeodomain (Figure 1). Phylogenetic analysis clearly places both genes within the Dlx clade (Figure 2). Genomic walking by library screening focussed on determining whether these genes are linked in a tail-to-tail arrangement and demonstrates that, if so, the two genes are a minimum of $41 \mathrm{~kb}$ apart (Figure 1). Southern hybridisation and direct sequencing of other Dlx positive phage clones failed to identify any additional Dlx sequences.

In-situ hybridisation of PlaDlxa and PlaDlxb showed that both genes are expressed in isolated cells in the early embryo, and in the apical ectoderm, prototroch, lateral ectoderm, ventral nerve cords, apical organ, suboesophageal ganglion and in a band around the stomach in the trochophore larva (Figure 3A-N). At the metatrochophore stage, expression of both genes becomes punctate and is primarily located in discrete cells in the vicinity of the stomach (Figure 3O,P). In early juvenile (post-metamorphosis) animals, PlaDlxa and PlaDlxb continue to be expressed in cells around the stomach; in older animals the majority of expression can be found in discrete cells near the intestine (Figure 3Q-T). No expression is observed in the parapodia at any stage. In 


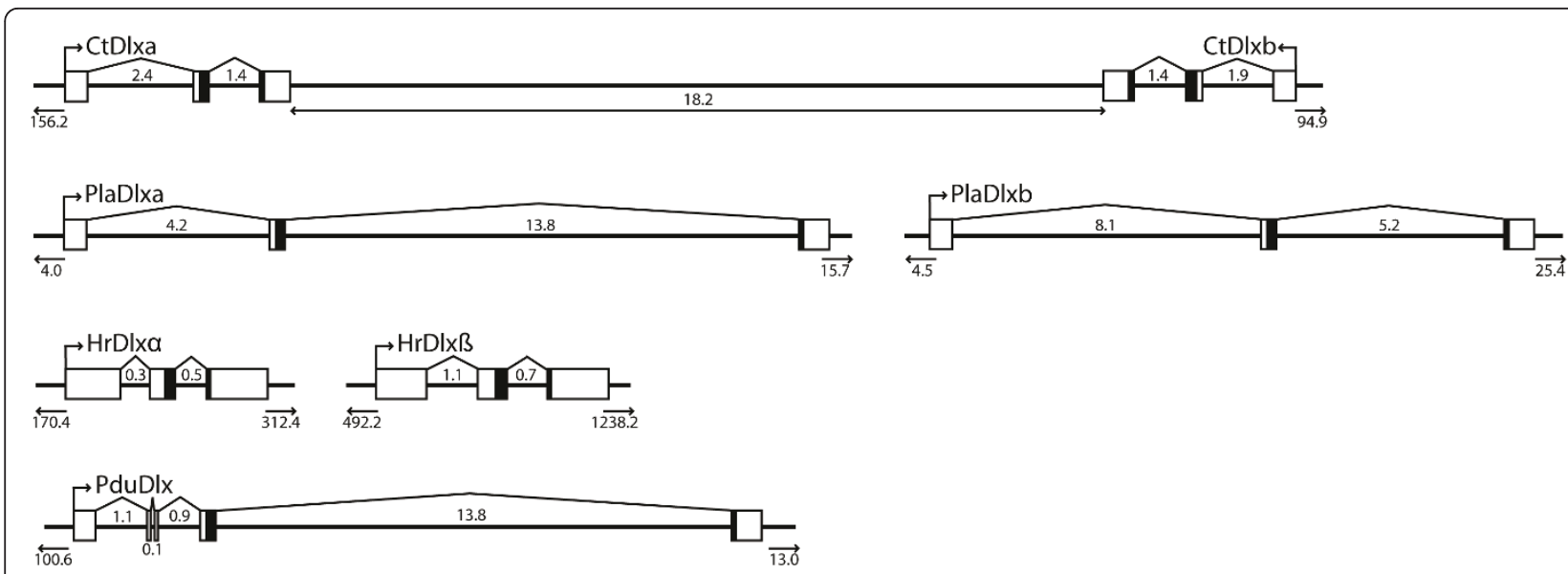

Figure 1 Genomic arrangement of annelid Dlx genes. Exons are indicated by boxes, introns are indicated by lines adjoining these. Distances are given in $\mathrm{kb}$, the homeodomain is shaded in black. The distance to the end of the scaffold or contig is indicated at the ends of each schematic.

general, the expression of the two genes is very similar, although there may be down-regulation of the expression of PlaDlxb at the early trochophore stage whilst PlaDlxa is still detectable (Figure $3 \mathrm{G}, \mathrm{H}$ ). In all cases where $D l x$ is detected, the precise pattern of cells expressing $D l x$ genes is variable between individuals, suggesting expression of $D l x$ is transient and dynamic. Control hybridisations with two non-overlapping probes for each gene gave consistent, comparable results (data not shown) and the same protocol with different genes gave clearly distinct staining patterns, as well as hybridisations with no probe producing no staining at all (Additional File 1).

The ElaV gene is a commonly used neuronal differentiation marker. We isolated a $670 \mathrm{bp}$ region of this gene [Genbank: accession number JN175270], phylogenetic analyses show that it is closely related to $P$. dumerilii ElaV (Additional File 2). PlaEla $V$ was also expressed in a punctate pattern in the stomach of juvenile $P$. lamarckii animals, reminiscent of the pattern seen for the P. lamarckii Dlx genes (Figure $3 \mathrm{U}$ ).

\section{C. teleta Dlx genes}

BLAST searches of the C. teleta trace files on NCBI and Genscan predictions based on genomic sequence of both the assembled genome on the JGI website and of a genomic contig generated manually from trace files resulted in the identification of two putative Dlx genes. One of these genes shares some conserved sequence motifs with PlaDlxa (see below and Figure 4) and also groups with it in the phylogenetic trees (see Figure 2), therefore we have designated it CtDlxa. The second gene appears more divergent and has hence been named $C t D l x b$. While the majority of the sequence of CtDlxa and $C t D l x b$ is quite divergent from each other, sequence similarity within the homeodomains is very high. Specifically, the nucleotide sequence of the homeoboxes are identical 5' of the homeobox intron (and for the first 12 nucleotides of this intron), and there are only three nucleotide differences at the 3' end, giving an overall similarity of $98.4 \%$ within this region.

While several different gene models are put forward for each gene, the Fgenesh ab initio models (CtDlxa: fgenesh1_pg.C_scaffold_237000015, CtDlxb: fgenesh1_pg.C_scaffold_237000013) predict an intron-exon structure typical for Dlx genes (three exons, with the second intron located between amino acids 44 and 45 of the homeodomain, Figure 1). As there are no EST sequences corresponding to either CtDlxa or CtDlxb these predictions cannot currently be confirmed. CtDlxa and $C t D l x b$ are located adjacent to each other in a tailto-tail orientation on scaffold 237 of the whole genome assembly. In this assembly, the intergenic distance is $18,352 \mathrm{bp}$, however there are some gaps within this region. In order to confirm the gene arrangement and intergenic distance, we completed our own assembly of C. teleta genomic trace files spanning these genes. This de novo assembly confirmed the tail-to-tail orientation of CtDlxa and CtDlxb, and puts the intergenic distance at $18,202 \mathrm{bp}$. It must be noted that some prediction methods identify a gene within this intergenic region (fgenesh1_pg.C_scaffold_237000014). However, this is only predicted by a few of the methods, it has no homology to any known sequence, and is not confirmed by EST's. We therefore consider it to be a false prediction.

\section{H. robusta Dlx genes}

As with $C$. teleta, BLAST searches of the $H$. robusta trace files on NCBI and Genscan predictions based on 


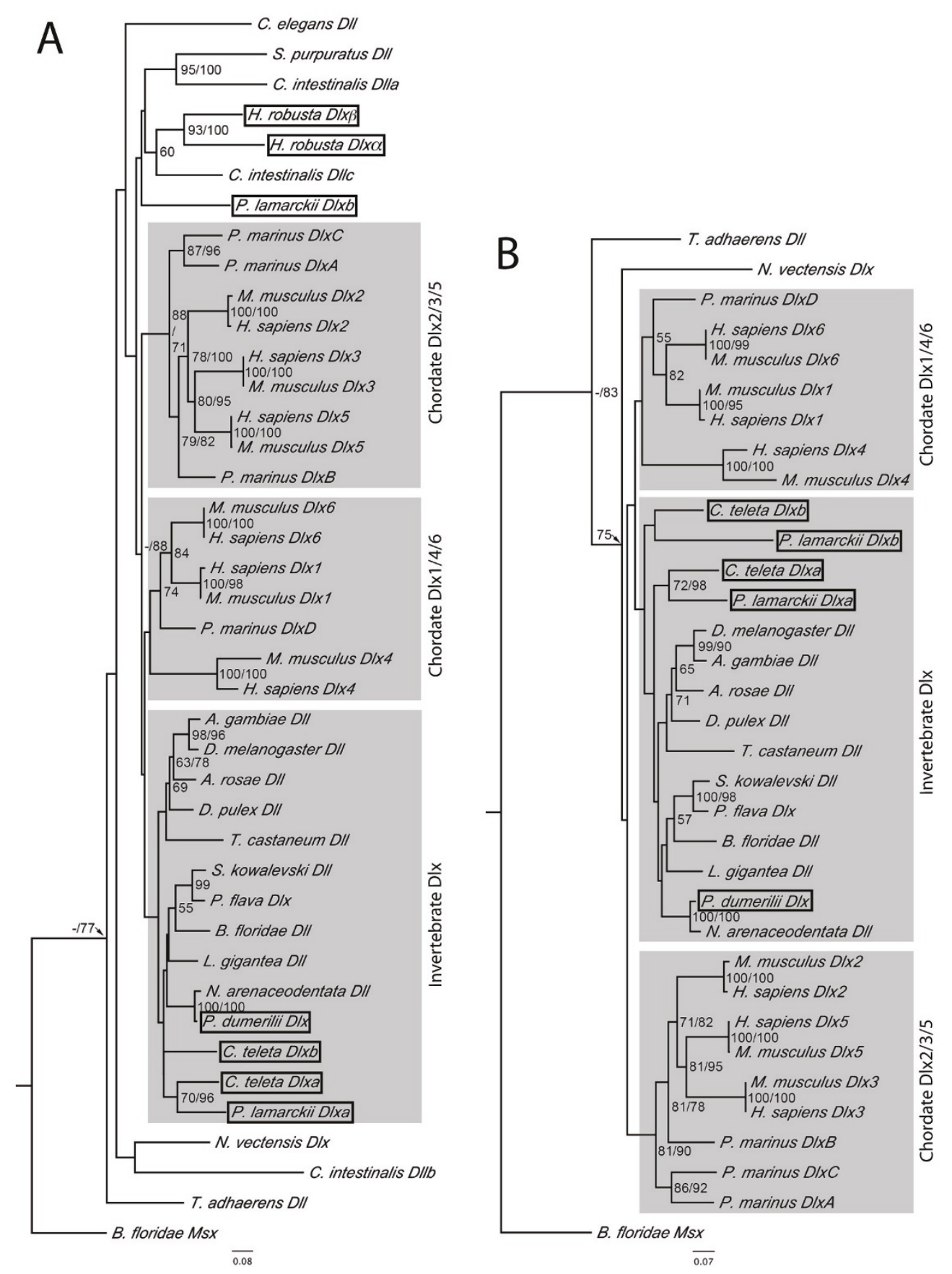

Figure 2 Neighbour-joining analysis of the phylogenetic relationships of annelid DIx genes. JTT method of substitution with 1000 bootstrap replicates. Percentage of bootstrap support is shown when over $50 \%$, followed by Bayesian posterior probability values where these are over $70 \%$. The trees are rooted with BfMsx, branch lengths are to scale (scale = substitutions/site). Sequences from representative species include Anopheles gambiae (arthropod), Athalia rosae (arthropod), Branchiostoma floridae (cephalochordate), Caenorhabditis elegans (nematode), Ciona intestinalis (ascidian), Drosophila melanogaster (arthropod), Daphnia pulex (crustacean), Homo sapiens (vertebrate), Lottia gigantea (mollusc), Mus musculus (vertebrate), Neanthes arenaceodentata (annelid), Nematostella vectensis (cnidarian), Ptychodera flava (hemichordate), Petromyzon marinus (chordate), Saccoglossus kowalevski (hemichordate), Strongylocentrotus purpuratus (echinoderm), Trichoplax adhaerens (placozoan), Tribolium castaneum (arthropod). Sequences that are the subject of this study are boxed. A. Analysis including highly divergent sequences. There is some support for the homology of $C$. teleta and P. lamarckii Dlxa sequences but the relationships of the other annelid Dlx sequences are unknown. H. robusta $D / x \alpha$ and $D / \beta$ group together with other sequences with longer branch lengths, possibly as a result of long branch attraction. B. Analysis excluding highly divergent sequences. As well as the grouping of $C$. teleta and $P$. lamarckii Dlxa genes, the D/xb genes of these two species now also show an affinity, but without strong support values. 

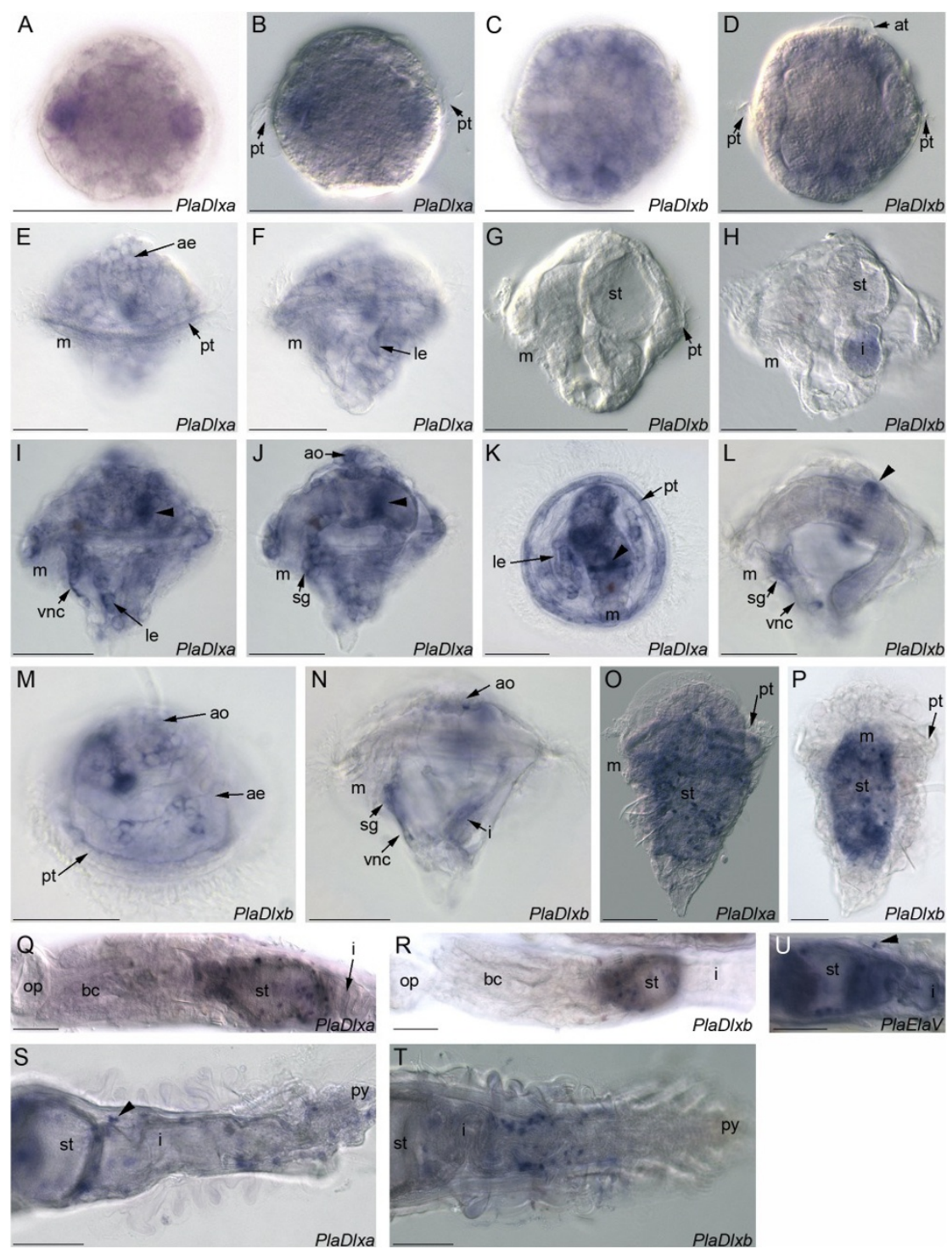

Figure 3 PlaDlxa and PlaDlxb expression during P. lamarckii development. Scale bars $=50 \mu \mathrm{m}$. The mouth $(\mathrm{m})$ is indicated as a reference point. A. Early embryo, brightfield. PlaDlxa expression is higher in some cells, which seem to vary between individuals. B. Same embryo as A, DIC. The prototroch is apparent, therefore these Dlx positive cells are mid-lateral. C. Early embryo, brightfield. PlaDlxb is expressed in multiple cells. D. Same embryo as C, DIC. Prototroch and apical tuft are clear, therefore PlaDlxb expression is in both episphere and hyposphere. E. Early trochophore, lateral view focused on episphere. PlaDlxa is expressed in apical ectoderm and prototroch. F. Same larva as E, hyposphere in focus. PlaDlxa is also expressed in lateral ectoderm. G. Early trochophore, lateral view. No PlaDlxb expression is detected. H. Early trochophore, more developed than G. No PlaDlxb expression is detected. The small patch of colouration in the intestinal lumen is attributable to background staining. I. Complete trochophore, lateral view. PlaDlxa is expressed in ventral nerve cords, lateral ectoderm, and a band around the stomach (arrowhead). J. Same larva as I, different focal plane. PlaDlxa is expressed in the suboesophageal ganglion and apical organ. The broad band around the stomach is still visible (arrowhead). K. Complete trochophore, ventral view. PlaDlxa expression in the prototroch is clear, as is the band around the stomach (arrowhead) and the lateral ectoderm. L. Complete trochophore, lateral view. PlaDlxb is expressed in the suboesophageal ganglion, ventral nerve cords, and a ring around the stomach (arrowhead). M. Complete trochophore, apical-lateral view. PlaDlxb is expressed in apical ectoderm, apical organ and prototroch. N. Complete trochophore, lateral view. PlaDlxb is expressed in the apical organ, suboesophageal ganglion, ventral nerve cords and intestine. O. Metatrochophore, lateral view. PlaD/xa has a punctate pattern throughout the animal. P. Metatrochophore, ventral view. PlaDlxb is primarily expressed in cells in the stomach area. Q. Young juvenile, ventral view. PlaDlxa is expressed in cells associated with the stomach. R. Young juvenile, dorsal view. PlaDlxb is expressed in cells associated with the stomach. S. Posterior of older juvenile, ventral view. PlaDlxa expression is in cells in the stomach, intestinal region, in individual cells in the pygidium and between intestinal folds (arrowhead). T. Posterior of older juvenile, ventral view. PlaDlxb expressing cells in the intestinal region. U. Older juvenile, PlaElaV (a neural marker) expression shown for comparison. PlaElaV is expressed in cells associated with the stomach, in some cells in the intestinal region, and in some cells in the parapodia (arrowhead). Apical ectoderm (ae), apical organ (ao), apical tuft (at), branchial crown (bc), intestine (i), lateral ectoderm (le), operculum (op), prototroch (pt), pygidium (py), stomach (st), suboesophageal ganglion (sg), ventral nerve cords (vnc). 


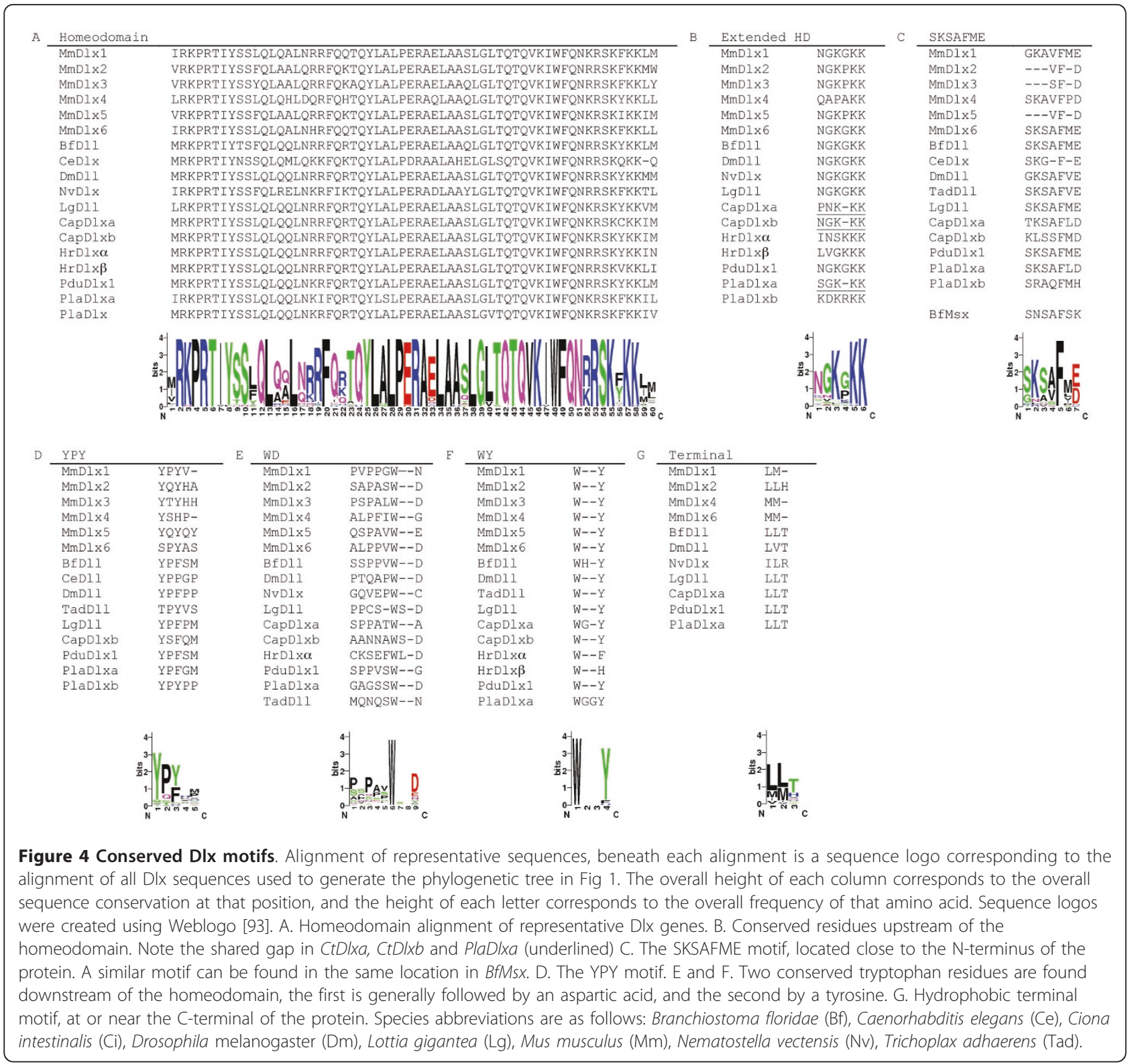

genomic sequence of the assembled genome on the JGI website resulted in the identification of two putative Dlx genes. Both sequences group with other Dlx genes in phylogenetic trees (Figure 2A). Outside the homeodomain, there is very little conservation between either $H$. robusta Dlx gene and any other Dlx gene; the genes have therefore been arbitrarily designated $\operatorname{HrDlx} \alpha$ and $H r D l \beta$. None of the gene models in the JGI assembly appear to predict the correct coding sequence for either $H r D l x \alpha$ or $H r D l \beta$ (the sequences are either truncated or missing part of the homeobox, but see fgenesh4_pg. C_scaffold_92000036 for the best prediction of $\mathrm{HrDl} \mathrm{l} \alpha$, and fgenesh4_pg.C_scaffold_41000062 for the best prediction of $H r D l \beta)$, and there are no corresponding EST sequences for this region. The coding sequences were therefore predicted by running approximately $10 \mathrm{~kb}$ of surrounding sequence through the GENSCAN program, which indicates that both genes are comprised of three exons with the second intron located between amino acids 44 and 45 of the homeodomain (Figure 1). In each case the sequences are much longer than the other annelid Dlx sequences ( $H r D l x \alpha$ and $H r D l \beta$ encode predicted proteins of 860 and 871 amino acids, respectively), and contain many poly-amino acid tracts, predominately polyglutamine.

HrDlx $\alpha$ can be found on scaffold 92, which is $486 \mathrm{~kb}$ in length. Fgenesh ab initio models predict a homeoboxcontaining neighbour of this gene, a likely Pknox family 
member. This gene is $23 \mathrm{~kb}$ away from $H r D l x \alpha$ and there are two other predicted genes in this intergenic distance. This is the only other homeobox gene on this scaffold. $H r D l \beta$ can be found on scaffold 41, which is $1.73 \mathrm{Mb}$ in length. There are no other homeobox genes on this scaffold. From the genome assembly it is clear that the two $H$. robusta Dlx genes are not closely linked; if they are on the same chromosome the minimum distance between the two genes is approximately $659 \mathrm{~kb}$.

\section{P. dumerilii Dlx genes}

A Dlx gene (PduDlx - Genbank AM114774) has previously been identified from $P$. dumerilii, it consists of five exons, including two microexons (which differs from the previously mentioned Dlx genes, Figure 1 ). Library screening was performed to determine whether a second Dlx gene is present in the $P$. dumerilii genome. All BAC and phage clones that produced a positive signal possessed $P d u D l x$, no additional Dlx sequences were obtained.

One $P d u D l x$ positive BAC clone has previously been completely sequenced [29], Genbank CT030672. This sequence was run through the online Genscan program [30] in order to predict open reading frames (ORFs). 10 ORFs were predicted by Genscan, none of these contained a homeobox sequence. Two of the predicted open reading frames are similar to each other $(22 \%$ identity, $49 \%$ positives) and both show high similarity to the 'ORF2' region of a zebrafish LINE element (accession AB211149; [31], Additional Files 3, 4 and 5).

\section{Conserved Dlx motifs}

In addition to the homeodomain and a number of amino acids adjacent to it (the 'extended homeodomain'), there are several other regions of conservation within the Dlx protein (Figure 4). The most notable of these is located close to the N-terminal of the protein and has been designated the 'SKSAFME' motif. This domain is present in most Dlx genes except for those in Nematostella vectensis, C. intestinalis, Strongylocentrotus purpuratus and $H$. robusta (the Petromyzon marinus sequences appear to be incomplete at the 5 ' end of the gene and were therefore excluded). The mammalian Dlx 2/3/5 clade possesses some residues with identity to this motif but lack the full sequence. A similar sequence is also found at the $\mathrm{N}$-terminal of the B. floridae Msx gene which was included in this study as an outgroup. Other conserved motifs include the 'YPY' motif, which is N-terminal to the homeodomain, two regions of conservation each surrounding a tryptophan residue $\mathrm{C}$-terminal to the homeodomain, and a hydrophobic domain at or near the $\mathrm{C}$-terminus of the protein.

Evolutionary relationships between annelid Dlx sequences In order to understand the relationship between the various Dlx genes and duplicates discovered above, a neighbour joining tree was created using an alignment of the homeodomain and its flanking sequences as well as some of the conserved motifs mentioned above from a range of taxa (for alignment see Additional File 6). Bayesian analysis was also performed. The resulting tree (Figure 2A) recovers the expected topology for mammalian Dlx genes, grouping Dlx $2 / 3 / 5$ and Dlx $1 / 4 / 6$ (although the latter group had weak bootstrap support). Arthropod Dlx genes formed a clade (with the exclusion of Tribolium castaneum Dll which had weak support) and the two hemichordate Dlx genes (Saccoglossus kowalevskii Dll and Ptychodera flava Dlx) were grouped together with high support. Annelid Dlx genes were generally not grouped together, although CtDlxa and PlaDlxa formed a well-supported clade. Several of the more divergent sequences (such as the $C$. intestinalis and $H$. robusta Dlx genes) were grouped together, suggestive of long branch attraction. The analysis was therefore repeated without these genes, which resulted in very little change to the topology of the tree, except that PlaDlxb now grouped with $C t D l x b$ with low support (Figure 2B).

\section{Gene conversion in C. teleta}

From the Dlx sequence alignments it became apparent that the two C. teleta Dlx genes demonstrated extremely high sequence similarity in the homeodomain region. This similarity was also observed at the nucleotide level. In order to examine whether this was a general feature of Dlx genes in taxa where two Dlx genes exist in an inverted pair, alignments of the nucleotide sequences of the homeoboxes were performed for each pair in each species (Figure 5). From this alignment, it is evident that the sequence identity seen between the two C. teleta genes does not exist in any of the other gene pairs investigated.

In order to test the significance of the amount of identity seen in the C. teleta Dlx genes, nucleotide alignments were run through the program Geneconv [32], see Additional File 7 for results. This program identified a fragment of $150 \mathrm{bp}$ (corresponding to the 5' part of the homeodomain and part of the intronic sequence) which is highly likely to be undergoing gene conversion in CtDlxa and CtDlxb. A second region corresponding to the 3' part of the homeodomain was also identified, however this had a tract length of only $31 \mathrm{bp}$. Ten other significant tracts were identified in both the $C$. teleta and P. lamarckii Dlx genes, however these were very short, ranging from 21-10 bp in length. The biological significance of these is uncertain given the level of sequence conservation normally seen in homeoboxes. The GC content of the tracts identified by Geneconv did not differ from the remainder of the sequence. 


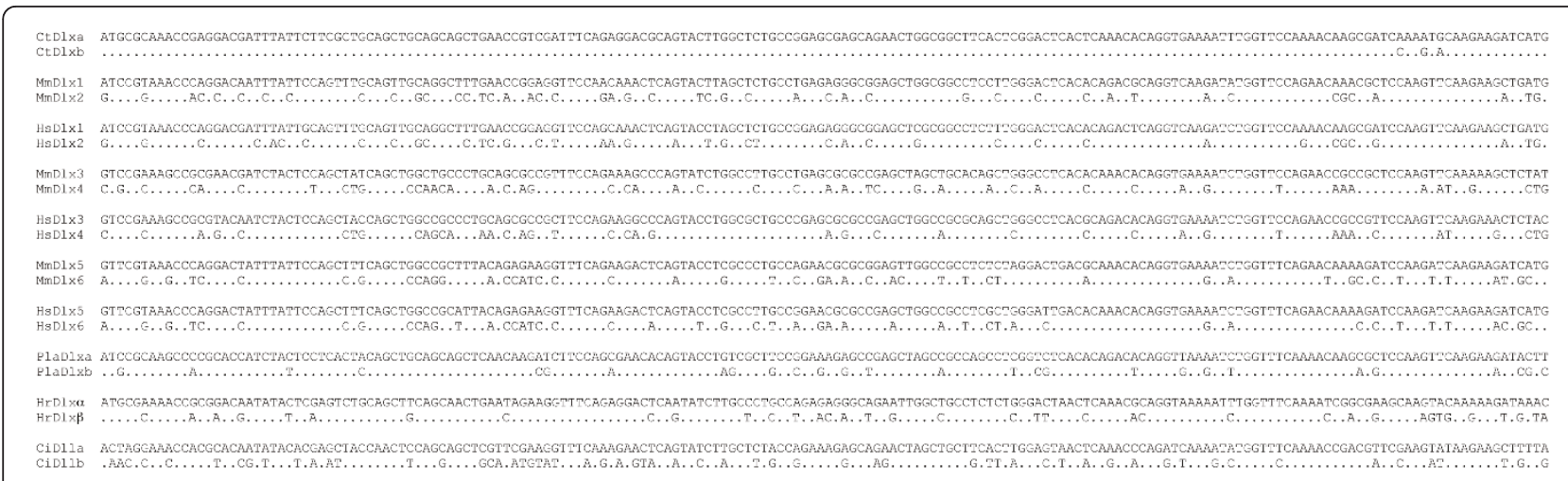

Figure 5 Sequence similarity at the nucleotide level in paired Dlx genes. Pairwise alignments of the homeobox from Dlx genes that are arranged as inverted pairs, as well as H. robusta and P. lamarckii Dlx genes. Conserved nucleotides are indicated by a dot. Nucleotide similarity is strikingly higher in the C. teleta Dlx genes than in any other gene pair.

\section{Discussion}

\section{Functions of conserved Dlx motifs}

The identification of several Dlx genes from annelids and comparisons with other taxa allowed the identification of several highly conserved domains within these sequences. These regions of amino acid conservation in Dlx genes from distantly related taxa are presumably functionally important. The SKSAFME domain is particularly well conserved and is situated close to the Nterminal of the protein. In many other homeodomain containing genes, a domain in this position is responsible for transcriptional regulation of downstream targets [33-35]. This domain has been identified individually in many classes of homeodomain genes and therefore is known by several names, including the Hep motif [35], octapeptide [36], TN domain [37], eh1 homology region [33,38], SNAG domain [39] and NK decapeptide [40]. A similar domain $(H N F-3)$ is found in unrelated Forkhead genes [41]. Apart from their shared location within the gene, some sequence similarity is evident when many different domains are aligned (see Additional File 8, adapted from [42], consensus sequences from $[33,35-38,41])$. The SKSAFME domain found in Dlx genes has previously been called the 'Hep' domain $[14,43]$, and shows some sequence similarity to these regions (particularly those found in Vent and Msx genes) in the alignment. It is therefore possible that the SKSAFME domain in Dlx genes functions to control transcription of downstream target genes.

As well as the Hep motif, many homeobox genes also encode a conserved hexapeptide motif located N-terminal of the homeodomain which encodes a central tryptophan residue $[38,44]$. This motif, which is also called the PID domain, is involved in binding PBX protein cofactors, increasing the specificity of DNA binding by the homeodomain $[45,46]$. No conserved motifs containing a tryptophan can be found upstream of the homeodomain in Dlx genes, however the two conserved tryptophan residues 3' of the homeodomain (Figure 4) may fulfil this cofactor binding role.

\section{Annelid DIx duplicates - one duplication?}

To date, duplicated Dlx genes have only been found in chordate lineages, therefore the discovery of multiple Dlx genes in several annelid lineages is surprising. In particular, the similarity in arrangement of C. teleta Dlx genes with those found in chordates (i.e., in an inverted tail-to-tail pair) is intriguing and poses the question of whether the annelid and chordate Dlx pairs arose as the result of an ancient Dlx duplication which has been followed by the loss of one gene in multiple other lineages (for example, in ecdysozoans, ambulacrarians and cephalochordates). Also there is a question as to whether there is some kind of selective advantage or constraint associated with having tandem duplicates linked in this way, or whether the arrangement has occurred by chance alone.

The phylogenetic analysis presented here does not present any evidence to suggest that the chordate and annelid Dlx genes arose from a common gene duplication, but there is limited resolution due to the relatively short sequence aligned and few phylogenetically informative residues, a problem commonly encountered with Dlx phylogenetic trees $[28,47]$. In any case, there is no evidence of close linkages of annelid Dlx genes with Hox genes, unlike the situation seen in chordates; the Pknox gene found near $\operatorname{HrDl} \alpha \alpha$ is distantly related to the Hox genes and unlikely to be significant, and while $P d u D l x$ is on the same chromosome as the Hox cluster in P. dumerilii, it is quite distant from it (Hui et al., submitted). While P. dumerilii and, presumably, the closely related $N$. arenaceodentata, appear to possess only one 
Dlx gene, all other annelids examined in this study possess two. These annelid duplicates could be the result of 1) independent duplications, 2) of a pre-annelid duplication followed by gene loss in P. dumerilii, or 3 ) by a duplication that occurred after the divergence of the $P$. dumerilii lineage from that of the other annelids studied. We favour the third scenario, given the grouping of PlaDlxa and CtDlxa (and, to a lesser extent, PlaDlxb and $C t D l x b)$ in the phylogenetic trees and the similarities seen within the sequences, i.e. the possession of one relatively prototypical Dlx gene which possesses the common motifs, and one more divergent Dlx. In addition, the $C$. teleta and P. lamarckii Dlx genes share some unusual changes, such as a deletion in the extended homeodomain motif, and a shared aspartic acid at the end of their SKSAFME motif (see Figure 4). We therefore tentatively conclude that the presence of two Dlx genes in these species is a consequence of a single duplication in the ancestor of C. teleta and P. lamarckii, rather than the slightly less well supported possibility that independent duplications in each lineage were followed by the divergence of one gene and the stasis of the other. The $H$. robusta Dlx genes are quite divergent from other annelid Dlx genes, therefore it is unclear whether the Dlx genes of $H$. robusta arose in an independent duplication or whether they may also be descended from a single duplication that gave rise to the $C$. teleta and P. lamarckii Dlx genes.

If the C. teleta, P. lamarckii, and possibly the $H$. robusta Dlx genes arose in a single duplication, is the sole Dlx gene in P. dumerilii a result of gene loss or divergence in the nereid lineage prior to the duplication? A recent paper has examined relationships between annelid families, and has demonstrated that, in general, annelids belong to one of two major clades, the Errantia (which includes $P$. dumerilii), or the Sedentaria (which includes C. teleta, P. lamarckii and $H$. robusta) [48]. Therefore, the most parsimonious hypothesis using the available data is that $P$. dumerilii diverged prior to a duplication in the lineage leading to C. teleta, H. robusta and possibly P. lamarckii (Figure 6). Further information regarding the Dlx gene complement of other Errantia species is required to confirm this proposal.

If the chordate and annelid duplicates are indeed independent, then the duplicated Dlx genes have converged on the same tail-to-tail genomic arrangement in at least two independent events. There are several other examples of homeobox genes being organised in this convergently transcribed manner, such as the engrailed and invected genes in hexapods [49], and the iroquois genes in multiple organisms [50,51]; these show both tail-totail and head-to-head organisation. Therefore, it appears that having duplicates arranged in this way occurs often and may well have some kind of selective advantage or constraint. Sharing of enhancer elements has been proposed for the engrailed and iroquois examples mentioned above, and, in vertebrates, enhancer sharing has been demonstrated for the Dlx $1 / 2$ and Dlx $5 / 6$ gene pairs [52-55]. Such enhancer sharing can result in

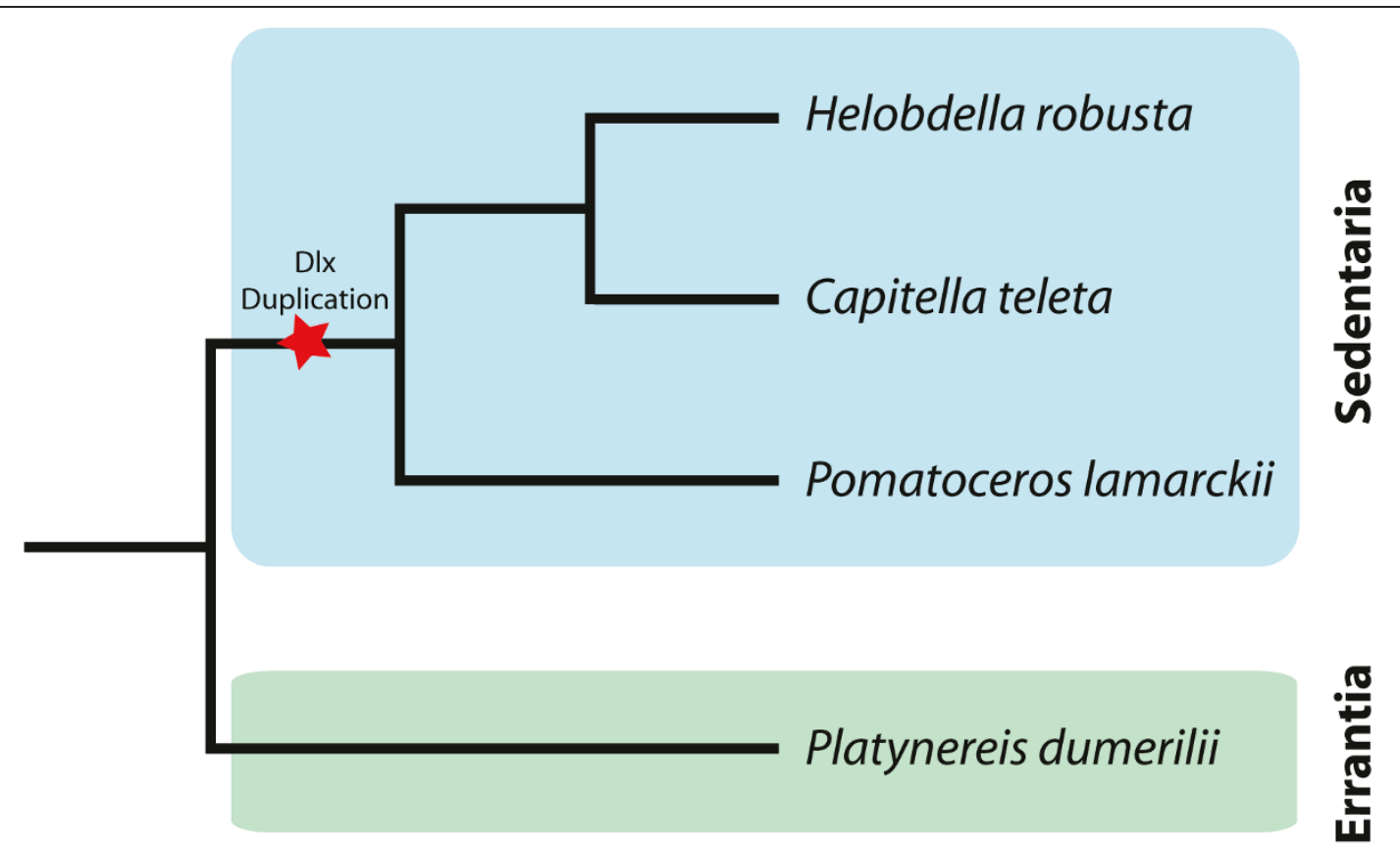

Figure 6 Hypothesized location of the Dlx gene duplication in an annelid phylogeny. The annelids depicted are restricted to those examined for Dlx content in this work. The topology of the phylogeny is based upon [48]. 
similar expression patterns, and may lead to selective advantage by allowing more precise transcriptional control of similar transcripts that act in a combinatorial manner, such as the Hox genes [56-59]. Therefore, the paired C. teleta and chordate Dlx genes may be the result of parallel evolution of a favourable gene arrangement. It is interesting to note that the P. lamarckii Dlx genes have very similar expression patterns, it will be interesting to discover whether this is due to linkage and enhancer sharing of the two genes once more genomic data is available.

\section{Duplicated annelid Dlx genes have divergent fates}

$C t D l x a$ and $C t D l x b$ are closely linked in a tail-to-tail organisation and are predicted to encode two quite divergent proteins. Despite this, there is 100\% similarity between the nucleotide sequences of the C. teleta Dlx genes in the 5' (pre-intron) part of the homeobox, and in the $5^{\prime}$ part of the intra-homeobox intron. There is also high similarity in the 3' part of the homeobox. The striking nucleotide identity between the two copies is higher than expected even if the sequences were constrained due to selection, especially as there is also conservation in silent sites. In addition, if selection were responsible for the maintenance of sequence a higher degree of similarity would be expected between $C$. teleta Dlx genes and those from other, related species. Figure 5 shows that this is clearly not the case. An alternative explanation is that the similarity is due to the genes being a product of a recent duplication, however this is unlikely as the remainder of the gene exhibits a high level of divergence.

This unexpectedly high level of conservation and the closely linked and inverted physical arrangement of the two genes (which is reminiscent of many other examples of unexpected nucleotide conservation in duplicated genes in the literature) is consistent with a proximitybased gene conversion mechanism. Gene conversion is the 'non-reciprocal transfer of information from one DNA duplex to another' [60], and concerted evolution by gene conversion has been documented in several $D$. melanogaster gene duplicates, such as Hsp70 and Hsp82 $[61,62], \alpha$-amylase [63,64], and trypsin [65], and also in putative antimicrobial proteins in C. elegans [66] and within the extensive palindromic sequences on human and chimp Y chromosomes [67]. Each of these examples documents gene conversion between genes that are closely linked in an inverted orientation. Examples of gene conversion in non-inverted duplicates also exist, for example, Nv1 neurotoxin genes in $N$. vectensis [68] and rRNA genes in D. melanogaster [69], as do examples of conversion of genes on different chromosomes [70].

Gene conversion could therefore explain the high nucleotide identity between the two $C$. teleta Dlx genes.
The program Geneconv is a statistical test for gene conversion, and it identifies 4 tracts that are likely to have undergone gene conversion in the C. teleta Dlx sequences and 8 tracts in the $P$. lamarckii Dlx sequences. However, the majority of these tracts are extremely short. It is likely that a minimum length of sequence homology is required for gene conversion to take place, it has been reported that at least $50 \mathrm{bp}$ of homology are required ([71] and references therein) and other studies have used a minimum tract length of $100 \mathrm{bp}$ to search for genes undergoing gene conversion [72]. Despite this, very short ( $<12 \mathrm{bp})$ gene conversion tract lengths have been reported for yeast [73]. In addition, the identification of gene conversion based on sequence similarity is complicated by the fact that the homeobox is a highly conserved sequence, therefore tracts of homology could occur by chance. Given that CtDlxb and Homo sapiens Dlx1 exhibit a tract of perfect homology of $25 \mathrm{bp}$, it is clear that this degree of similarity is indeed possible and can occur by chance alone. It is therefore likely that the phenomenon of gene conversion is restricted only to the 5' part of the homeobox and some of the adjoining intron of CtDlxa and CtDlxb, and possibly also to the 3' part of the homeodomain, i.e, the region of the gene which is most highly conserved across taxa. This 'mosaic' pattern of gene conversion within a gene is well documented [72], and gene conversion in homeobox genes has been described before, in the hexapod engrailed and invected genes [49]. While duplicated Dlx genes are seen elsewhere in the animal kingdom, the C. teleta Dlx genes are the only known example where gene conversion seems to be taking place (see Figure 5). The mammalian genes, despite also being arranged in a tail-to-tail orientation and having a shorter intergenic distance $[53,55]$ show a much higher level of sequence divergence in the homeobox. This might be explained by higher rates of evolution in these genes, which would allow them to 'escape' gene conversion [66,74]. Mammalian Dlx4 genes have been shown to have elevated sequence divergence (in comparison to other mammalian Dlx genes), possibly due to reduced selection pressure because of the redundancy that exists within mammalian Dlx genes [75]. This redundancy may also allow elevated evolution rates in the other mammalian Dlx genes.

Within the annelids, $H$. robusta and $P$. lamarckii also have duplicated Dlx genes which do not appear to be subject to gene conversion. The $H$. robusta genes are not closely linked, are much longer than Dlx genes found in other species, and lack most of the conserved motifs found in other Dlx genes. It therefore appears that the $H$. robusta Dlx genes have been subject to much higher rates of evolution than those of other annelid species, and that any selective pressure or 
constraint to keep the Dlx duplicates together has been overcome in this species.

While the genomic arrangement of P. lamarckii Dlx genes is unknown, they are at least $41 \mathrm{~kb}$ apart if they are tail to tail, or $8.5 \mathrm{~kb}$ apart if they are head to head. Therefore, if they are linked in a tail to tail orientation they are not as closely linked as the C. teleta Dlx gene pair. There is no evidence of gene conversion between PlaDlxa and PlaDlxb. While PlaDlxa shows similar branch lengths to CtDlxa, the branch lengths of PlaDlxb are significantly longer, indicating a higher rate of evolution of this particular gene. The similar expression patterns of PlaDlxa and PlaDlxb indicate that the two genes may be co-expressed, possibly pointing to shared cis-regulatory sequences if the two genes are indeed linked.

Regardless of whether they are the result of a single or multiple gene duplications, the paired Dlx genes of these annelid species are not behaving in a similar manner post-duplication. In the current post-genomic era, largescale studies are being conducted in order to understand the dynamics of gene duplication and the effects of these events on the evolution of the organisms involved. General trends have been difficult to identify, and it appears that the chances of a newly duplicated gene being retained in the genome is a largely neutral process [76]. From the example of duplicated Dlx genes in annelids, we can once again observe that there is no general pattern evident in their sequence evolution that explains the behaviour of duplicated genes.

\section{The role of Dlx genes in annelid development}

This study has found that Dlx genes are unlikely to be playing a major role in appendage formation in $P$. lamarckii. Throughout development, PlaDlxa and PlaDlxb are expressed in what is interpreted to be neural tissue, but the expression is dynamic and turned off in various structures (such as the ventral nerve cords) after their formation. We therefore hypothesise that PlaDlxa and PlaDlxb are involved in the differentiation of the nervous system. In support of this, the $P$. lamarckii homologue of ElaV, a neural differentiation marker $[27,77,78]$ is expressed in a punctate and dynamic pattern in the juvenile stomach, which is very similar to Dlx.

While Dlx is expressed in the parapodia of another polychaete, C. variopedatus [3], it is not clear that this expression is indicative of a role in the process of appendage formation or if it is associated with the development of sensory or neural structures. Indeed, in $N$. arenaceodentata, Dlx expression observed at the base of the parapodia is interpreted as being associated with the parapodial ganglia [28]. In all four annelids studied to date, Dlx expression is observed in what is assumed to be developing neural tissue. Dlx expression is also observed in early embryogenesis in P. lamarckii; where this has been demonstrated in other organisms it has been implicated in the control of cellular movements during gastrulation [8-10,79]. Despite the expression of P. lamarckii Dlx genes in widely conserved expression domains, the absence of an appendage formation role is surprising. There is a possibility that a third P. lamarckii Dlx gene exists and is involved in appendage formation (however this is unlikely given the thoroughness of the screening) or that the lack of Dlx expression in the appendages in $P$. lamarckii represents a taxon specific loss.

It is important to note that while Dlx is expressed in the appendages of many organisms, in some cases 'limb' Dlx is more likely to be playing a role in limb-associated neural structures [5]. In some cases it has been shown that Dlx is not an absolute requirement for appendage outgrowth. Dlx knockouts have been performed in spiders; in injected embryos appendages do form but they lack the most distal region [23]. In fact, some arthropod appendages do not exhibit any Dlx expression at all [80]. The vertebrate condition is complicated by the redundant nature of the multiple Dlx genes, and single gene mutants have no visible defects in limb formation. Combinatorial Dlx mutants exhibit malformations of the distal limb (reviewed in [2]), but the limb itself still forms. Therefore, the 'conserved' appendage function of Dlx genes relates to its role in the development of the distal appendage. Perhaps, then, the distal appendage has been lost in the evolution of annelid parapodia, or gained independently in arthropods and vertebrates. There are clear examples of the Dlx gene being coopted into the formation of novel appendage-like structures, such as echinoderm tube feet and ascidian siphons $[3,81]$, so a gain of function in both arthropods and vertebrates is certainly possible.

Dlx is associated with the nervous system in a multitude of taxa. Therefore, this is a much more likely ancestral role for the gene than is limb formation. This is supported by the very early origin of the gene in metazoan diversification, i.e, prior to the radiation of bilaterians, the ancestor of which may have lacked limbs altogether (see [5] for discussion]. However, in some cases Dlx expression has been observed very early in embryogenesis [[8,9], this study], therefore we suggest that the ancestral role of Dlx could also be in a specific type of morphogenetic process that is utilised in numerous ways throughout animal development. A similar hypothesis has been put forward by Irvine and colleagues [20]. One potential morphological process is evagination, as Dlx expression is seen during early embryonic stages (gastrulation), which may use similar cellular movements to the evaginations required during 
appendage formation [20]. Another potential morphogenetic process that Dlx may be involved in is cell adhesion. In C. elegans, RNAi knockdown of Dlx (ceh-43) causes the loss of cells though a hole in the hypodermis and an eventual rupture of the animal [6], therefore a role of Dlx in cell adhesion was proposed. Interestingly, cell adhesion can be mediated by neurons, which can act as guidance cues for cellular movements $[6,82]$, providing a potential link for Dlx in both morphogenetic processes and in the nervous system. Elements of either, or both, of these processes may then have been coopted into the process of appendage formation in several taxa.

\section{Conclusions}

We have presented here the first examples of duplicated Dlx genes outside the chordates. We propose that a duplication of the Dlx gene occurred within the annelid lineage, after the split of $P$. dumerilli from the lineage leading to $H$. robusta, $C$. teleta and $P$. lamarckii. The two C. teleta Dlx genes are closely linked and have been subject to gene conversion, the two $H$. robusta Dlx genes are not closely linked and exhibit divergent gene sequences, and the $P$. lamarckii genes do not show gene conversion, but have very similar expression patterns. Therefore, in these three cases, the duplicated Dlx genes have had very different post-duplication fates.

\section{Methods}

Animal sources and library construction

Adult $P$. lamarckii were collected and spawned as described [83]. Genomic DNA was extracted from sperm and a phage library was created by Lofstrand Labs, Maryland, USA using the LambdaFIX II (Xho1) vector, and amplified. Genomic DNA was partially digested with Sau2A1, filled in and cloned. The average insert size of the library was calculated to be 16-17 kb. XL1-Blue MRA(P2) cells (Agilent) were then transfected and plated to give approximately $4 \times$ genome coverage for library screening by hybridisation.

Sperm from a single male $P$. dumerilii worm was prepared in agarose plugs. DNA was then extracted from the plugs before being sent to Loftstrand Labs for library construction as outlined above. The average insert size was also calculated to be $16-17 \mathrm{~kb}$. This library was plated to give approximately $5 \times$ genome coverage for screening by hybridisation.

Details of the $P$. dumerilii BAC genomic library can be found in [29].

\section{Library screening}

A 5' fragment (811 bp) of $P$. dumerilii Dlx (accession AM114774.1) was generated from a cDNA clone using specific primers (PdDLL5' - 5' GGG ATT ACA GCC
TGA GAC and PdDLL3' - 5' TTT ACC TGA GTT TGG GTG), and a labelled probe was synthesised using the PCR DIG labelling mix (Roche) following the manufacturer's instructions. The $P$. lamarckii genomic phage library was then screened for Dlx using standard methods [84] with a hybridisation temperature of $37^{\circ} \mathrm{C}$ and two post-hybridisation washes in $2 \times$ SSC, $0.1 \%$ SDS for 15 minutes at room temperature (RT), followed by two washes in $0.5 \times \mathrm{SSC}, 0.1 \% \mathrm{SDS}$ for 15 minutes at $55^{\circ} \mathrm{C}$. Signals were detected using a 1:20,000 dilution of antidigoxygenin-AP (Roche) and CDP-Star chemiluminescent substrate (Roche) as per the manufacturer's instructions. Two phage plaques producing strong signals and giving different restriction digest patterns were chosen for complete sequencing. Each clone was sonicated and A-overhangs added. They were then ligated into the pGem-T Easy vector and sequenced using T3 and $\mathrm{T} 7$ primers. Vector trimming was performed manually and contig assembly was performed using the DNAStar software (low stringency settings, no vector trimming). Gaps in the phage insert sequences were closed by sequencing using specific primers. These sequences were checked for homology to known Dlx genes using BLASTX, and intronic arrangement was predicted using the GENSCAN software http://genes. mit.edu/GENSCAN.html. In order to determine if the two discovered Dlx genes were closely linked, genomic walking was performed by designing probes to the end sequences of the parental phage and screening the library as detailed above, except that hybridisation temperatures were raised to $42^{\circ} \mathrm{C}$ and post-hybridisation washes were increased to $65^{\circ} \mathrm{C}$. Resulting phage sequences were checked for the presence of Dlx genes by PCR, and long range PCR was performed using the Expand Long Template PCR kit (Roche) in order to determine phage length.

The $P$. dumerilii genomic phage and BAC libraries were screened using the same Dlx probe and conditions as outlined above. Positive BAC clones were ordered from BACPAC resources and checked for the presence of $P d u D l x$ by PCR using the specific primers shown above. The degree of overlap of BAC sequences was determined by end-sequencing using vector primers.

\section{Manual trace assembly}

The $C$. teleta and $H$. robusta trace archives http://www. ncbi.nlm.nih.gov/Traces/trace.cgi were searched for Dlx by using the discontiguous megaBLAST algorithm and the homeodomain and flanking sequences of PlaDlxa and PlaDlxb as the query sequence. Entire C. teleta and $H$. robusta Dlx sequences and their orientations were obtained by 'walking' from the trace files obtained in the above searches. This involved blasting the terminal 200 bp of sequence against the trace archive, downloading 
overlapping traces and assembling the contigs using the SeqMan assembler (DNAStar suite). Assembly settings were default, with a medium level of end trimming, a minimum match size of 12 and minimum match percentage of 80 .

\section{Rapid Amplification of cDNA Ends}

RACE-ready cDNA libraries were constructed from mixed larval $P$. lamarckii total RNA and RACE performed using the BD SMART RACE cDNA Amplification Kit (Clontech) as per the manufacturer's instructions, except that the annealing temperatures for the touchdown PCR were lowered (see brackets after each primer listing for initial annealing temperatures). Primer sequences were as follows:

PlaDlxa 5': 5' CGACAGGTACTGTGTTCGCTGGAAGATC $\left(70^{\circ} \mathrm{C}\right)$

PlaDlxa 5' nested: 5' GAGGAGTAGATGGTGCGGGGCTTGCGGA $\left(66^{\circ} \mathrm{C}\right)$

PlaDlxa 3': 5' GAGAGAGCCAGATGAGCCCACGCCCAAG $\left(70^{\circ} \mathrm{C}\right)$

PlaDlxa 3' nested: 5' CGGTCTCACACAGACACAGGTNAARATH $\left(60^{\circ} \mathrm{C}\right)$

PlaDlxb 5': 5' GCATTTGACCTTGGTTCTGCGAGGGAAT $\left(70^{\circ} \mathrm{C}\right)$

PlaDlxb 5' nested: 5' TTCACCTGAGTCTGTGTGACGCCAAGGC $\left(66^{\circ} \mathrm{C}\right)$

PlaDlxb 3': 5' AGAATGAACCTGGCATATCCTCCAAGGA $\left(70^{\circ} \mathrm{C}\right)$

PlaDlxb 3' nested: 5' GCCTTGGCGTCACACAGACTCAGGTGAA $\left(66^{\circ} \mathrm{C}\right)$

\section{Phylogenetic analysis}

Dlx sequences (and the B. floridae Msx sequence, which was used as an outgroup) were retrieved from NCBI http://www.ncbi.nlm.nih.gov/. Accession numbers can be found in Additional File 9. Sequences were formatted in BBEdit Lite 6.1 [85] before being aligned using clustalx [86] with reduced gap penalties (for pairwise alignments the gap opening penalty was set to 5 and the gap extension penalty to 0.05 ; for the multiple alignment the gap opening penalty was set to 5 and the gap extension penalty to 0.1 ). Alignments were manually edited using Se-Al v2.0 [87]. Two alignments were produced, one with a comprehensive Dlx dataset and another with the most divergent taxa removed in order to reduce the probability of tree topology disruption. Phylogenetic trees were built using the Phylip 3.66 package of programs [88]. A neighbour joining tree was constructed using the JTT matrix with 1000 bootstraps, and a consensus tree produced. Bayesian analysis was performed using MrBayes v3.1.2 [89], with two runs for 2.5 (full dataset) or 1.5 (dataset with divergent taxa removed) million generations (sampled every 100, first 250 trees discarded as burn-in) using the mixed amino acid substitution model and the gamma likelihood model for among-site rate variation. Trees were viewed and edited using FigTree [90].

\section{Detection of gene conversion}

Alignments of genomic Dlx sequences from C. teleta, $P$. lamarckii, $P$. dumerilii and $H$. robusta (padded by an additional 5000 bp both up and downstream) were performed using the program CHAOS with DIALIGN [91]. The alignment was searched for regions of potential gene conversion between $C$. teleta or P. lamarckii sequences using the program GENECONV [32] with default settings except that monomorphic sites were included.

For regions for which gene conversion was deemed to be likely, GC content was determined manually for the third codon positions of exons and for intronic sequence.

\section{In-situ hybridisation}

Larvae and juveniles were cultured as described [83] and fixed according to a previously reported protocol [92]. Larvae $36 \mathrm{hpf}$ or older were relaxed by the addition of an equal amount of $7 \% \mathrm{MgCl}_{2}$ in FSW to the dish contents. Probes were synthesised using DIG RNA labelling mix (Roche) according to the manufacturer's instructions. For each gene probes were designed 3' of the homeodomain, the PlaDlxa probe was 491 bp long and synthesised using the primers PlaDlxa Fwd (5' CCCTCTAACCCCACAGCCTCCG) and PlaDlxa Rev (5' CCGTAGCCACCCCAGCCCCCGT), the PlaDlxb probe was 576 bp long and synthesised using PlaDlxb Fwd (5' TTCCCTCGCAGAATCAAGGTCA) and PlaDlxb Rev (5' CGCCACCATACGGGTAATAACC). The PlaElaV sequence was isolated via degenerate touchdown PCR using the primers ElaV-1 (5' CGMTAYGGSTTYGTNAACTA) and ElaV-2 (5' BACDGCBCCRAANGGNCCRAA) with an annealing temperature of $60^{\circ} \mathrm{C}$ which was decreased by $0.5^{\circ} \mathrm{C}$ per cycle for 40 cycles. The resulting product was used as a probe and labelled as outlined above.

Prior to hybridisation fixed animals were stepped into cold PBT $(1 \times$ PBS, $0.1 \mathrm{M}$ Tween-20) with 5 minute washes. Juveniles were decalcified in PBTE $(1 \times$ PBS, 0.1 M Tween-20, 0.05 M EGTA) for approximately $30 \mathrm{~min}$ utes until calcified tube was no longer visible. Samples were then treated with $0.5 \mu \mathrm{g} / \mathrm{ml}$ proteinase $\mathrm{K}$ at $37^{\circ} \mathrm{C}$ for 10 minutes and were post-fixed in $4 \%$ paraformaldehyde in $1 \times$ PBS for 45 minutes at room temperature. Hybridisation was performed as described in [92], but using a hybridisation temperature of $55^{\circ} \mathrm{C}$. Negative controls that lacked probe were performed and showed no staining (see Additional File 1). The reproducibility of 
the PlaDlxa and PlaDlxb stainings was confirmed by using two probes from different regions of each gene (data not shown) as well as by comparison to nonneural genes with different patterns of staining and which do not stain the gut (see Additional File 1), thus confirming that the staining around the gut in PlaDlxa and PlaDlxb experiments is unlikely to be due to probe trapping and instead is likely to reflect staining of visceral nerve cells. Stained specimens were cleared in $60 \%$ glycerol and photographed using a Zeiss Axioskop 2 and the Axiovision 4 software or a Zeiss Axioplan 2 and the Openlab software.

\section{Additional material}

Additional file 1: In-situ hybridisation controls. Negative in situ controls lacking probe and positive controls with an unrelated gene. Additional file 2: Phylogenetic position of PlaElaV. Neighbour-joining tree showing the relationships between ElaV genes from different taxa. Additional file 3: Consensus sequence of PduL2. Sequence derived from alignment of sequences found in several different BAC clones. Additional file 4: The domain organisation of PduL2. Graphic depicting the endonuclease and reverse transcriptase domains of PduL2. Additional file 5: Phylogenetic position of PduL2. Neighbour joining tree showing the relationships between PduL2 and other LINE elements. Additional file 6: Dlx alignment. Alignment of homeodomain and other conserved regions of Dlx genes used for phylogenetic analysis.

Additional file 7: Geneconv output. Tracts of Dlx sequences likely to be undergoing gene conversion as predicted by Geneconv.

Additional file 8: Hep-like domains. Alignment of N-terminal Hep-like domains of selected homebox and forkhead genes.

Additional file 9: Sequences used in phylogenetic analyses.

Accession numbers and database sources for sequences used in phylogenetic analyses.

\section{Acknowledgements}

The authors would like to thank Carola Burgtorf (Berlin) for providing $P$. dumerilii material for phage library construction, and Guillaume Balavoine (Paris) for providing the P. dumerilii D/x CDNA clone. CM was supported by a Commonwealth Scholarship. Work in the authors' laboratory is supported by the BBSRC and the School of Biology, University of St Andrews.

\section{Author details}

${ }^{1}$ The Scottish Oceans Institute, University of St Andrews, East Sands, St Andrews KY16 8LB, UK. ${ }^{2}$ Department of Zoology, University of Oxford, South Parks Road, Oxford OX1 3PS, UK. ${ }^{3}$ School of Biological Sciences, University of Queensland, Brisbane, Queensland 4072, Australia.

\section{Authors' contributions}

CM carried out molecular genetic studies, participated in the design of the study and drafted the manuscript. JT performed the initial Dlx probe synthesis and library screen of the $P$. lamarckii phage library. NK sequenced the initial Dlx positive $P$. lamarckii phage clones and performed the first round of genomic walking in this organism. DEKF conceived of the study, participated in its design and was involved in drafting the manuscript. All authors have read and approved the final manuscript.

Received: 22 April 2011 Accepted: 16 August 2011 Published: 16 August 2011
References

1. Cohen SM, Bronner G, Kuttner F, Jurgens $G$, Jackle H: Distal-less encodes a homeodomain protein required for limb development in Drosophila. Nature 1989, 338:432-434.

2. Panganiban GEF, Rubenstein JLR: Developmental functions of the Distalless/Dlx homeobox genes. Development 2002, 129:4371-4386.

3. Panganiban GEF, Irvine SQ, Lowe CJ, Roehl H, Corley LS, Sherbon B, Grenier JK, Fallon JF, Kimble J, Walker M, Wray GA, Swalla BJ, Martindale MQ, Carroll SB: The origin and evolution of animal appendages. Proc Natl Acad Sci USA 1997, 94:5162-5166.

4. Cohen SM, Jürgens G: Proximal-distal pattern formation in Drosophila: cell autonomous requirement for Distal-less gene activity in limb development. EMBO J 1989, 8:2045-2055.

5. Mittmann B, Scholtz G: Distal-less expression in embryos of Limulus polyplremus (Chelicerata, Xiphosura) and Lepisma saccharina (Insecta, Zygentoma) suggests a role in the development of mechanoreceptors, chemoreceptors, and the CNS. Dev Genes Evol 2001, 211:232-243.

6. Aspock G, Burglin TR: The Caenorhabditis elegans Distal-less ortholog ceh43 is required for development of the anterior hypodermis. Dev Dyn 2001, 222:403-409.

7. Freeman MR, Delrow J, Kim J, Johnson E, Doe CQ: Unwrapping glial biology: $\mathrm{Gcm}$ target genes regulating glial development, diversification, and function. Neuron 2003, 38:567-580.

8. Asano M, Emori Y, Saigo K, Shiokawa K: Isolation and characterization of a Xenopus cDNA which encodes a homeodomain highly homologous to Drosophila Distal-Less. The Journal of Biological Chemistry 1992, 267:5044-5047.

9. Lee SE, Jacobs DK: Expression of Distal-less in molluscan eggs, embryos, and larvae. Evolution \& Development 1999, 1:172-179.

10. Holland ND, Panganiban GEF, Henyey EL, Holland LZ: Sequence and developmental expression of AmphiDII, an amphioxus Distal-less gene transcribed in the ectoderm, epidermis and nervous system: Insights into evolution of craniate forebrain and neural crest. Development 1996, 122:2911-2920.

11. Gauchat D, Mazet F, Berney C, Schummer M, Kreger S, Pawlowski J, Galliot B: Evolution of Antp-class genes and differential expression of Hydra Hox/paraHox genes in anterior patterning. Proc Natl Acad Sci USA 2000, 97:4493-4498.

12. Ryan JF, Burton PM, Mazza ME, Kwong GK, Mullikin JC, Finnerty JR: The cnidarian-bilaterian ancestor possessed at least 56 homeoboxes: evidence from the starlet sea anemone, Nematostella vectensis. Genome Biol 2006, 7:R64.

13. Ryan JF, Mazza ME, Pang K, Matus DQ, Baxevanis AD, Martindale MQ, Finnerty JR: Pre-bilaterian origins of the Hox cluster and the Hox code: Evidence from the sea anemone, Nematostella vectensis. PLOS ONE 2007, 2:e153.

14. Monteiro AS, Schierwater B, Dellaporta SL, Holland PWH: A low diversity of ANTP class homeobox genes in Placozoa. Evolution \& Development 2006, 8:174-182.

15. Larroux C, Luke GN, Koopman P, Rokhsar DS, Shimeld SM, Degnan BM: Genesis and expansion of metazoan transcription factor gene classes. Mol Biol Evol 2008, 25:980-996.

16. Howard-Ashby M, Materna SC, Brown CT, Chen L, Cameron RA, Davidson EH: Identification and characterization of homeobox transcription factor genes in Strongylocentrotus purpuratus, and their expression in embryonic development. Dev Biol 2006, 300:74-89.

17. Stock DW, Ellies DL, Zhao ZY, Ekker M, Ruddle FH, Weiss KM: The evolution of the vertebrate Dlx gene family. Proc Natl Acad Sci USA 1996, 93:10858-10863.

18. Amores A, Force A, Yan YL, Joly L, Amemiya C, Fritz A, Ho RK, Langeland JA, Prince V, Wang YL, Westerfield M, Ekker M, Postlethwait JH: Zebrafish hox clusters and vertebrate genome evolution. Science 1998, 282:1711-1714.

19. Ellies DL, Stock DW, Hatch G, Giroux G, Weiss KM, Ekker M: Relationship between the genomic organization and the overlapping embryonic expression patterns of the zebrafish Dlx genes. Genomics 1997, 45:580-590.

20. Irvine SQ, Cangiano MC, Millette BJ, Gutter ES: Non-overlapping expression patterns of the clustered DII-A/B genes in the ascidian Ciona intestinalis. J Exp Zool B Mol Dev Evol 2007, 308B:428-441. 
21. Castro LFC, Holland PWH: Chromosomal mapping of ANTP class homeobox genes in amphioxus: piecing together ancestral genomes. Evolution \& Development 2003, 5:459-465.

22. Niimi T, Kuwayama H, Yaginuma T: Larval RNAi applied to the analysis of postembryonic development in the ladybird beetle, Harmonia axyridis. Journal of Insect Biotechnology and Sericology 2005, 74:95-102.

23. Schoppmeier M, Damen WG: Double-stranded RNA interference in the spider Cupiennius salei: the role of Distal-less is evolutionarily conserved in arthropod appendage formation. Dev Genes Evol 2001, 211:76-82.

24. Scholtz G, Mittmann B, Gerberding M: The pattern of Distal-less expression in the mouthparts of crustaceans, myriapods and insects: new evidence for a gnathobasic mandible and the common origin of Mandibulata. Int J Dev Biol 1998, 42:801-810.

25. Panganiban GEF, Sebring A, Nagy LM, Carroll SB: The development of crustacean limbs and the evolution of arthropods. Science 1995, 270:1363-1366.

26. Lee $\mathrm{SE}$, Gates RD, Jacobs DK: The isolation of a Distal-less gene fragment from two molluscs. Dev Genes Evol 2001, 211:506-508.

27. Denes AS, Jékely $G$, Steinmetz PR, Raible $F$, Snyman H, Prud'homme $B$ Ferrier DEK, Balavoine G, Arendt D: Molecular architecture of annelid nerve cord supports common origin of nervous system centralization in Bilateria. Cell 2007, 129:277-288.

28. Winchell CJ, Valencia JE, Jacobs DK: Expression of Distal-less, dachshund, and optomotor blind in Neanthes arenaceodentata (Annelida, Nereididae) does not support homology of appendage-forming mechanisms across the Bilateria. Dev Genes Evol 2010.

29. Raible F, Tessmar-Raible K, Osoegawa K, Wincker P, Jubin C, Balavoine G, Ferrier DEK, Benes V, de Jong P, Weissenbach J, Bork P, Arendt D: Vertebrate-type intron-rich genes in the marine annelid Platynereis dumerilii. Science 2005, 310:1325-1326

30. Burge C, Karlin S: Prediction of complete gene structures in human genomic DNA. J Mol Biol 1997, 268:78-94.

31. Sugano T, Kajikawa M, Okada N: Isolation and characterization of retrotransposition-competent LINEs from zebrafish. Gene 2006, 365:74-82.

32. Sawyer S: GENECONV: A computer package for the statistical detection of gene conversion. Book GENECONV: A computer package for the statistical detection of gene conversion City: Distributed by the author, Department of Mathematics, Washington University in St Louis; 1999, (Editor ed.^eds.).

33. Smith ST, Jaynes JB: A conserved region of engrailed, shared among all en-, gsc-, Nk1-, Nk2- and msh-class homeoproteins, mediates active transcriptional repression in vivo. Development 1996, 122:3141-3150.

34. Masson N, Greene WK, Rabbitts TH: Optimal activation of an endogenous gene by $\mathrm{HOX} 11$ requires the $\mathrm{NH} 2$-terminal 50 amino acids. Mol Cell Biol 1998, 18:3502-3508.

35. Allen JD, Lints T, Jenkins NA, Copeland NG, Strasser A, Harvey RP, Adams JM: Novel murine homeo box gene on chromosome 1 expressed in specific hematopoietic lineages and during embryogenesis. Genes Dev 1991, 5:509-520.

36. Galliot B, de Vargas C, Miller DJ: Evolution of homeobox genes: Q50 Paired-like genes founded the Paired class. Dev Genes Evol 1999, 209:186-197.

37. Harvey RP: NK-2 homeobox genes and heart development. Dev Biol 1996, 178:203-216.

38. Bürglin TR: A comprehensive classification of homeobox genes. In Guidebook to the Homeobox Genes. Edited by: Duboule D. Oxford: Oxford University Press; 1994:.

39. Grimes HL, Chan TO, Zweidler-McKay PA, Tong B, Tsichlis PN: The Gfi-1 proto-oncoprotein contains a novel transcriptional repressor domain SNAG, and inhibits G1 arrest induced by interleukin-2 withdrawal. Mol Cell Biol 1996, 16:6263-6272.

40. Watada H, Mirmira RG, Kalamaras J, German MS: Intramolecular control of transcriptional activity by the NK2-specific domain in NK-2 homeodomain proteins. Proc Natl Acad Sci USA 2000, 97:9443-9448.

41. Shimeld SM: A transcriptional modification motif encoded by homeobox and fork head genes. FEBS Lett 1997, 410:124-125.

42. Luke GN: The NK homeobox gene cluster of Branchiostoma floridae. Thesis University of Reading, School of Biological Sciences; 2004.

43. Monteiro AS: Early evolution of homeobox genes. Thesis Universidade do Porto, Instituto de Ciências Biomédicas de Abel Salazar; 2006.
44. der Rieden PM, Mainguy G, Woltering JM, Durston AJ: Homeodomain to hexapeptide or PBC-interaction-domain distance: size apparently matters. Trends Genet 2004, 20:76-79.

45. Chang CP, Shen WF, Rozenfeld S, Lawrence HJ, Largman C, Cleary ML: Pbx proteins display hexapeptide-dependent cooperative DNA binding with a subset of Hox proteins. Gene Dev 1995, 9:663-674.

46. Neuteboom ST, Murre C: Pbx raises the DNA binding specificity but not the selectivity of antennapedia Hox proteins. Mol Cell Biol 1997, 17:4696-4706.

47. Stock DW: The Dlx gene complement of the leopard shark, Triakis semifasciata, resembles that of mammals: Implications for genomic and morphological evolution of jawed vertebrates. Genetics 2005, 169:807-817.

48. Struck TH, Paul C, Hill N, Hartmann S, Hösel C, Kube M, Lieb B, Meyer A, Tiedemann R, Purschke G, Bleidorn C: Phylogenomic analyses unravel annelid evolution. Nature 2011, 471:95-98.

49. Peel AD, Telford MJ, Akam M: The evolution of hexapod engrailed-family genes: evidence for conservation and concerted evolution. Proc Bio/ Sci 2006, 273:1733-1742.

50. Irimia M, Maeso I, Garcia-Fernàndez J: Convergent evolution of clustering of Iroquois homeobox genes across metazoans. Mol Biol Evol 2008, 25:1521-1525

51. Takatori N, Butts T, Candiani S, Pestarino M, Ferrier DEK, Saiga $H$ Holland PWH: Comprehensive survey and classification of homeobox genes in the genome of amphioxus, Branchiostoma floridae. Dev Genes Evol 2008.

52. Sumiyama K, Ruddle FH: Regulation of Dlx3 gene expression in visceral arches by evolutionarily conserved enhancer elements. Proc Natl Acad Sci USA 2003, 100:4030-4034.

53. Ghanem N, Jarinova O, Amores A, Long QM, Hatch G, Park BK, Rubenstein JLR, Ekker M: Regulatory roles of conserved intergenic domains in vertebrate Dlx bigene clusters. Genome Res 2003, 13:533-543.

54. Park BK, Sperber SM, Choudhury A, Ghanem N, Hatch GT, Sharpe PT, Thomas BL, Ekker M: Intergenic enhancers with distinct activities regulate Dlx gene expression in the mesenchyme of the branchial arches. Dev Biol 2004, 268:532-545.

55. Sumiyama K, Irvine SQ, Stock DW, Weiss KM, Kawasaki K, Shimizu N, Shashikant CS, Miller W, Ruddle FH: Genomic structure and functional control of the Dlx3-7 bigene cluster. Proc Natl Acad Sci USA 2002, 99:780-785.

56. Gould A, Morrison A, Sproat G, White RA, Krumlauf R: Positive crossregulation and enhancer sharing: two mechanisms for specifying overlapping Hox expression patterns. Genes Dev 1997, 11:900-913.

57. Kmita M, van Der Hoeven F, Zákány J, Krumlauf R, Duboule D: Mechanisms of Hox gene colinearity: transposition of the anterior Hoxb1 gene into the posterior HoxD complex. Genes Dev 2000, 14:198-211.

58. Kmita M, Duboule D: Organizing axes in time and space; 25 years of colinear tinkering. Science 2003, 301:331-333.

59. Sharpe J, Nonchev S, Gould A, Whiting J, Krumlauf R: Selectivity, sharing and competitive interactions in the regulation of Hoxb genes. EMBO J 1998, 17:1788-1798.

60. Szostak JW, Orr-Weaver TL, Rothstein RJ, Stahl FW: The double-strandbreak repair model for recombination. Cell 1983, 33:25-35.

61. Benedict MQ, Levine BJ, Ke ZX, Cockburn AF, Seawright JA: Precise limitation of concerted evolution to ORFs in mosquito Hsp82 genes. Insect Mol Biol 1996, 5:73-79.

62. Leigh Brown AJ, Ish-Horowicz D: Evolution of the $87 \mathrm{~A}$ and $87 \mathrm{C}$ heatshock loci in Drosophila. Nature 1981, 290:677-682.

63. Hickey DA, Bally-Cuif L, Abukashawa S, Payant V, Benkel BF: Concerted evolution of duplicated protein-coding genes in Drosophila. Proc Natl Acad Sci USA 1991, 88:1611-1615.

64. Shibata H, Yamazaki T: Molecular evolution of the duplicated Amy locus in the Drosophila melanogaster species subgroup: concerted evolution only in the coding region and an excess of nonsynonymous substitutions in speciation. Genetics 1995, 141:223-236.

65. Wang S, Magoulas C, Hickey D: Concerted evolution within a trypsin gene cluster in Drosophila. Mol Biol Evol 1999, 16:1117-1124.

66. Thomas $\mathrm{JH}$ : Concerted evolution of two novel protein families in Caenorhabditis species. Genetics 2006, 172:2269-2281.

67. Rozen S, Skaletsky H, Marszalek JD, Minx PJ, Cordum HS, Waterston RH, Wilson RK, Page DC: Abundant gene conversion between arms of 
palindromes in human and ape $\mathrm{Y}$ chromosomes. Nature 2003, 423:873-876

68. Moran Y, Weinberger H, Sullivan JC, Reitzel AM, Finnerty JR, Gurevitz M: Concerted evolution of sea anemone neurotoxin genes is revealed through analysis of the Nematostella vectensis genome. Mol Biol Evol 2008, 25:737-747.

69. Eickbush TH, Eickbush DG: Finely orchestrated movements: evolution of the ribosomal RNA genes. Genetics 2007, 175:477-485.

70. Xu S, Clark T, Zheng H, Vang S, Li R, Wong GK, Wang J, Zheng X: Gene conversion in the rice genome. BMC Genomics 2008, 9:93.

71. Walsh JB: Sequence-dependent gene conversion: can duplicated genes diverge fast enough to escape conversion? Genetics 1987, 117:543-557.

72. Carson AR, Scherer SW: Identifying concerted evolution and gene conversion in mammalian gene pairs lasting over 100 million years. BMC Evol Biol 2009, 9:156.

73. Palmer S, Schildkraut E, Lazarin R, Nguyen J, Nickoloff JA: Gene conversion tracts in Saccharomyces cerevisiae can be extremely short and highly directional. Nucleic Acids Res 2003, 31:1164-1173.

74. Beisswanger S, Stephan W: Evidence that strong positive selection drives neofunctionalization in the tandemly duplicated polyhomeotic genes in Drosophila. Proc Natl Acad Sci USA 2008, 105:5447-5452.

75. Coubrough ML, Bendall AJ: Impaired nuclear import of mammalian Dlx4 proteins as a consequence of rapid sequence divergence. Exp Cell Res 2006, 312:3880-3891

76. Meisel RP: Evolutionary dynamics of recently duplicated genes: selective constraints on diverging paralogs in the Drosophila pseudoobscura genome. J Mol Evol 2009, 69:81-93.

77. Meyer NP, Seaver EC: Neurogenesis in an annelid: characterization of brain neural precursors in the polychaete Capitella sp. I. Dev Biol 2009, 335:237-252.

78. Soller M, White K: Elav. Curr Biol 2004, 14:R53.

79. Irvine SQ: Whole-mount in situ hybridization of small invertebrate embryos using laboratory mini-columns. BioTechniques 2007, 43:764-768.

80. Khila A, Grbić M: Gene silencing in the spider mite Tetranychus urticae: dsRNA and siRNA parental silencing of the Distal-less gene. Dev Genes Evol 2007, 217:241-251.

81. Lowe CJ, Wray GA: Radical alterations in the roles of homeobox genes during echinoderm evolution. Nature 1997, 389:718-721.

82. Chin-Sang ID, George SE, Ding M, Moseley SL, Lynch AS, Chisholm AD: The ephrin VAB-2/EFN-1 functions in neuronal signaling to regulate epidermal morphogenesis in C. elegans. Cell 1999, 99:781-790.

83. MCDougall C, Chen WC, Shimeld SM, Ferrier DEK: The development of the larval nervous system, musculature and ciliary bands of Pomatoceros lamarckii (Annelida): heterochrony in polychaetes. Front Zool 2006, 3:16.

84. Sambrook J, Russell DW: Molecular Cloning: A Laboratory Manual. 3 edition. New York: Cold Spring Harbor; 2001.

85. Siegel R, Woolsey P, Correia J, Hueras J, Kalkwarf S: BBEdit Lite. Book BBEdit Lite. 6.1.2 edition. City: Bare Bones Software; 2001, (Editor ed.^eds.).

86. Thompson JD, Gibson TJ, Plewniak F, Jeanmougin F, Higgins DG: The CLUSTAL_X windows interface: flexible strategies for multiple sequence alignment aided by quality analysis tools. Nucleic Acids Res 1997, 25:4876-4882.

87. Rambaut A: Se-Al. Book Se-Al City; 1996, (Editor ed.^eds.) v2.0a11 edition.

88. Felsenstein J: PHYLIP (Phylogeny Inference Package). Book PHYLIP (Phylogeny Inference Package) City: Department of Genetics, University of Washington; 1995, (Editor ed.^eds.).

89. Huelsenbeck JP, Ronquist F: MRBAYES: Bayesian inference of phylogenetic trees. Bioinformatics 2001, 17:754-755.

90. Rambaut A: FigTree. Book FigTree. 1.1.1 edition. City: University of Edinburgh; 2006, (Editor ed.^eds.).

91. Brudno M, Steinkamp R, Morgenstern B: The CHAOS/DIALIGN WWW server for multiple alignment of genomic sequences. Nucleic Acids Res 2004, 32: W41-44.

92. Giusti AF, Hinman VF, Degnan SM, Degnan BM, Morse DE: Expression of a $\mathrm{Scr} / \mathrm{Hox} 5$ gene in the larval central nervous system of the gastropod Haliotis, a non-segmented spiralian lophotrochozoan. Evol Dev 2001, 2:294-302.

93. Crooks GE, Hon G, Chandonia J-M, Brenner SE: WebLogo: a sequence logo generator. Genome Res 2004, 14:1188-1190.

\section{doi:10.1186/1471-2148-11-241}

Cite this article as: McDougall et al: Annelid Distal-less/Dlx duplications reveal varied post-duplication fates. BMC Evolutionary Biology 2011 11:241.

\section{Submit your next manuscript to BioMed Central and take full advantage of:}

- Convenient online submission

- Thorough peer review

- No space constraints or color figure charges

- Immediate publication on acceptance

- Inclusion in PubMed, CAS, Scopus and Google Scholar

- Research which is freely available for redistribution 